ARTICLE

Received 10 Jul 2012 | Accepted 9 Jan 2013 | Published 12 Feb $2013 \quad$ DOl: 10.1038/ncomms2481

\title{
Aromatic porous-honeycomb electrodes for a sodium-organic energy storage device
}

Ken Sakaushi ${ }^{1,2,3}$, Eiji Hosono ${ }^{3}$, Georg Nickerl ${ }^{2}$, Thomas Gemming ${ }^{1}$, Haoshen Zhou $^{3}$, Stefan Kaskel ${ }^{2}$ \& Jürgen Eckert ${ }^{1,4}$

Rechargeable batteries using organic electrodes and sodium as a charge carrier can be highperformance, affordable energy storage devices due to the abundance of both sodium and organic materials. However, only few organic materials have been found to be active in sodium battery systems. Here we report a high-performance sodium-based energy storage device using a bipolar porous organic electrode constituted of aromatic rings in a porous-honeycomb structure. Unlike typical organic electrodes in sodium battery systems, the bipolar porous organic electrode has a high specific power of $10 \mathrm{~kW} \mathrm{~kg}^{-1}$, specific energy of $500 \mathrm{Wh} \mathrm{kg}^{-1}$, and over 7,000 cycle life retaining $80 \%$ of its initial capacity in half-cells. The use of bipolar porous organic electrode in a sodium-organic energy storage device would significantly enhance cost-effectiveness, and reduce the dependency on limited natural resources. The present findings suggest that bipolar porous organic electrode provides a new material platform for the development of a rechargeable energy storage technology.

\footnotetext{
${ }^{1}$ IFW Dresden, Institute for Complex Materials, Helmholtzstrasse 20, D-01069 Dresden, Germany. ${ }^{2}$ TU Dresden, Department of Inorganic Chemistry, Bergstrasse 66, D-01069 Dresden, Germany. ${ }^{3}$ National Institute of Advanced Industrial Science and Technology, Energy Technology Research Institute, 1-1-1 Umezono, Tsukuba 305-8568, Japan. ${ }^{4}$ TU Dresden, Institute of Materials Science, Helmholtzstrasse 7, D-01069 Dresden, Germany. Correspondence and requests for materials should be addressed to K.S. (email: k.sakaushi@ifw-dresden.de).
} 
$\mathrm{N}$ ext-generation rechargeable batteries are key devices for the successful development of green technologies ${ }^{1}$, for example, a grid system combined with large-scale storage and renewable energy, and electric vehicles. Currently, rechargeable lithium batteries are the leading candidate for such utilizations. However, abundance of commercially viable lithium source is low, which may be detrimental to future costs and energy supply stability. In spite of this, there is a huge demand for lithium batteries to be used in a variety of devices, for example, portable electronic devices and electronic vehicles ${ }^{1-6}$.

A key issue for successfully developing green technologies is affordability. There is an urgent need for alternative energy storage devices with a performance comparable to, or better than rechargeable lithium batteries. One possible approach is to use sodium as an alternative charge carrier ${ }^{3-18}$ to lithium, as the cost of sodium carbonate $\left(\mathrm{Na}_{2} \mathrm{CO}_{3}\right)$, for example, is only $3 \%$ of $\mathrm{Li}_{2} \mathrm{CO}_{3}$ (ref. 5). Another even more effective approach to improving affordability is to replace the current metal-based electrodes with organic materials ${ }^{19-27}$ that are more abundant in nature. Since the advent of conductive polymers ${ }^{28}$ and reversible redox polymers $^{22}$, a large number of $p-, n$ - and bipolar organic electrodes have been investigated for energy storage devices due to their low-cost and possible applications in flexible plastic batteries $^{21}$. Although there is a long history of research in sodium-based energy storage devices, there have been only a few reports of organic materials applied to rechargeable sodium batteries, for example, polyparaphenylene and sodium terephthalate $23,24,27$, and often they are only suitable as the anode. Finding a new, suitable group of organic materials for use as cathodes in sodium batteries could stimulate the development of sodium-based energy storage devices and meet the requirement of next-generation batteries, namely high-specific energy and power, and most importantly, affordability.

We report bipolar porous polymeric frameworks as a new class of affordable organic electrodes for a sodium-based energy storage device: an aromatic porous-honeycomb cathode, which shows a long cycle life of over 7,000 cycles and performances comparable to lithium-ion batteries, which are a high-specific power of $10 \mathrm{~kW} \mathrm{~kg}^{-1}$ and a specific energy of $500 \mathrm{Wh} \mathrm{kg}^{-1}$ based on the weight of the organic electrode in half-cells.

\section{Results}

Physical characterization of the porous organic electrode. The bipolar porous organic electrode (BPOE) is a porous-honeycomb, polymeric framework consisting of benzene rings and triazine rings in two-dimensional (2D) structure (Fig. 1a) ${ }^{29,30}$. Using high-resolution transmission electron microscopy, we have confirmed that the BPOE has a sheet-like morphology, which is with $\sim 300 \mathrm{~nm}$ wide (Fig. 1b) and typically we observed $<10$ stacking layers, giving a thickness of $\sim 4 \mathrm{~nm}$ (Fig. $1 \mathrm{~b}$ inset). Raman spectroscopy (Fig. 1c), Fourier-transform infrared (FT-IR) spectroscopy (Supplementary Fig. S1) and X-ray diffractometry (Supplementary Fig. S2) gives a further details about the BPOE: This framework is formed as a short-range-ordered 2D structure with the stacking of each $2 \mathrm{D}$ unit (Fig. 1a) in a noncoplanar fashion ${ }^{29-31}$ as the global structure. Raman spectroscopy measurements (RSMs) allow to reveal the electronic structure of materials (= information about a structural periodicity of a material $)^{32-34}$. Especially, graphite and graphene have been extensively researched concerning their electronic structure by $\mathrm{RSMs}^{32-36}$. The $G$ peak is produced by the doubly degenerated zone centre $E_{2 g}$ mode, which is a motion of atoms in the $2 \mathrm{D}$ honeycomb structure ${ }^{32-34}$. This $G$ peak also appears in the porous-graphene at same position, as well as graphene. Furthermore, carbon nitride formed in $2 \mathrm{D}$ honeycomb structure shows the $G$ peak at $\sim 1,600 \mathrm{~cm}^{-1}$ (refs 35,36). Therefore, the $G$ peak at $\sim 1,600 \mathrm{~cm}^{-1}$ in Fig. $2 \mathrm{c}$ reveals the existence of a $2 \mathrm{D}$ poroushoneycomb structure, which is constituted by benzene rings and triazine rings. This structure, which is revealed by Raman spectroscopy, FT-IR spectroscopy and X-ray diffractometry, is comparable to hard carbon, a disordered carbon consisting of single graphene sheets stacked at random angles ${ }^{37}$. Electron energy-loss spectroscopy measurements show a $1 \mathrm{~s} \rightarrow \pi^{*}$ transition, which reveals the $s p^{2}$-hybridization for carbon and nitrogen at $285 \mathrm{eV}$ and $400 \mathrm{eV}$, respectively, (Fig. 1d) and the fine structure of the $\mathrm{C}-K$ and $\mathrm{N}-K$ edges also suggest a graphitic network with $s p^{2}$-bonding ${ }^{38}$. Indeed, we investigated the porous structure of the BPOE by nitrogen physisorption experiments (Fig. 2a). Its poresize distribution confirmed the existence of micropores of ca.1.4 nm (Fig. 1a), which was observed by previous reports ${ }^{29-31}$ (Fig. 2b). From these measurements, we confirmed the formation of a short-range-ordered $2 \mathrm{D}$ polymeric framework constituted by aromatic rings. Therefore, the BPOE shows adjustable electronic properties and controllable semiconducting features emerging from their structural periodicity comparable to $2 \mathrm{D}$ atomic crystals, such as multilayer graphene, and a choice of monomer as a building block $^{39-45}$. Here we demonstrate that the bipolar characters of the BPOE required for high-performance electrochemical properties are preserved even in a sodium battery system.

Electrochemical characterizations of the BPOE. Electrochemical impedance spectroscopy (EIS) measurements were carried out at $3.3 \mathrm{~V}$ versus $\mathrm{Na} / \mathrm{Na}^{+}$( $p$-doping process, Fig. $3 \mathrm{a}, \mathrm{b}$ ) and $2.3 \mathrm{~V}$ versus $\mathrm{Na} / \mathrm{Na}^{+}$(n-doping process, Fig. $3 c, d$ ) after achieving each quasi-equilibrium state ${ }^{46}$ in order to probe the physical and/or chemical phenomena at the interface between the BPOE and the electrolyte solution. A frequency range of $10 \mathrm{mHz}-10 \mathrm{kHz}$ with an amplitude of $10 \mathrm{mV}$ was applied in all EIS measurements. The Nyquist plots obtained by the EIS measurements were fitted using an equivalent circuit based on the Randels model ${ }^{29,47}$ showing in Fig. 3a,c, where $R$ is the electrolyte resistance, $\mathrm{CPE}=\left\{T_{\mathrm{CPE}}(j \omega)^{\alpha}\right\}^{-1}$ is a constant phase element with $\omega$ being the angular frequency and $\alpha$ an empirical electrode roughness parameter, and where $Z_{\mathrm{w}}$ is the Warburg impedance indicating a diffusion-limited electrochemical reaction. Each Nyquist plot above and below $2.8 \mathrm{~V}$ versus $\mathrm{Na} / \mathrm{Na}^{+}$shows a semicircle at high frequencies suggesting charge transfer at the polymeric framework/electrolyte $(1 \mathrm{M} \mathrm{NaClO}$ in propylene carbonate (PC)) interface and a characteristic linear diffusion-limited response at a tilt angle of close to $45^{\circ}$ at low frequencies indicating incorporation of the ion in the electrode materials ${ }^{17,29,47}$. The FT-IR and RSMs (Fig. 3e,f) confirmed the coordination of the anion $\left(\mathrm{ClO}_{4}^{-}\right)$in the polymeric framework, which was electrochemically incorporated. The $\mathrm{ClO}_{4}^{-}$doped $\mathrm{BPOE}$ is indicated as $\mathrm{I} ; 1 \mathrm{M} \mathrm{NaClO}{ }_{4}$ in $\mathrm{PC}$ is indicated as II; and PC is indicated as III. In Fig. 3e, which shows the Raman spectra, the peaks assigned 1 originate from PC. The peak $2 \mathrm{~A}$ in II $\left(935 \mathrm{~cm}^{-1}\right)$ is the infrared-inactive, but is Ramanactive $v_{1}$ mode for free $\mathrm{ClO}_{4}^{-}$(refs 48-50). This Raman-active $v_{1}$ mode and the signals form PC were not detected for I, which means that there is no residual electrolyte in I. In Fig. 3f, which shows the FT-IR spectra, the peak $2 \mathrm{~B}$ in $\mathrm{I}\left(881 \mathrm{~cm}^{-1}\right)$ is the infrared-active $v_{1}$ mode for $\mathrm{ClO}_{4}^{-}$(refs 48,51). The infraredinactive $v_{1}$ mode becomes infrared-active due to destruction of the symmetry by the coordination to host compounds. In our case, the destruction of the symmetry is induced by the electrochemical $p$-doping, which creates a coordination of $\mathrm{ClO}_{4}^{-}$ to the BPOE. The peaks assigned $1^{\prime}$ in II and III (Fig. 3f) originate from PC. The peak 3 in I (Fig. 3f) can be assigned to aromatic $\mathrm{C}-\mathrm{H}$ out-of-plane bend or 1,4-disubstituted benzene rings in the BPOE (ref. 29). From these spectroscopy measure- 
a

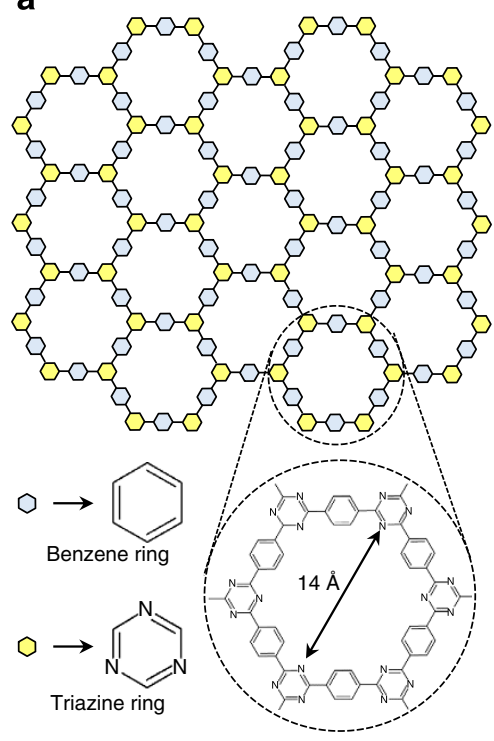

b

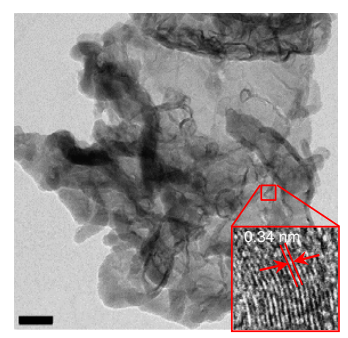

C

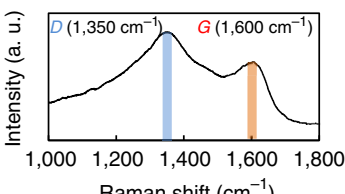

d

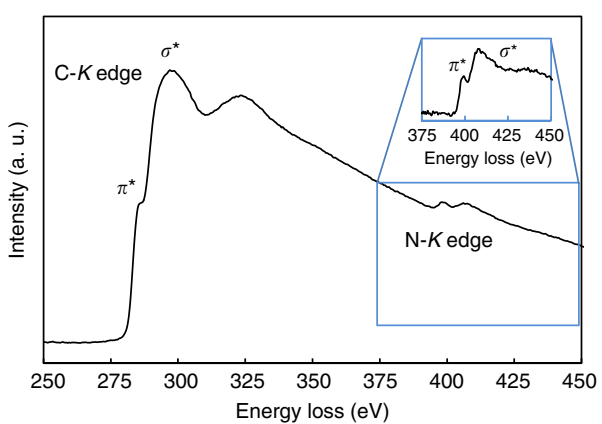

Figure 1 | Structure and spectroscopy measurements for BPOE. (a) Schematic illustration of the ideal BPOE having a porous-honeycomb structure with a pore diameter of $14 \AA$. The $2 \mathrm{D}$ structure of the BPOE is constituted by triazine rings and benzene rings. (b) Transmission electron microscopy image of the BPOE showing a sheet-like morphology. The scale bar indicates $100 \mathrm{~nm}$. The inset shows a cross-section of a multilayer BPOE, stacking of about 10 layers. (c) Raman spectrum of the BPOE at a laser excitation of $632.8 \mathrm{~nm}$. The existence of the $G$ peak reveals the graphene-like 2D structure. (d) Electron energyloss spectrum of the carbon and nitrogen $K$ edges recorded in the BPOE. The inset shows the $\mathrm{N}-K$ edge with subtraction of the background. The existence of $s p^{2}$-hybridized carbon and nitrogen atoms reveals the formation of graphitic network constituted by triazine and benzene rings. a.u., arbitrary unit.
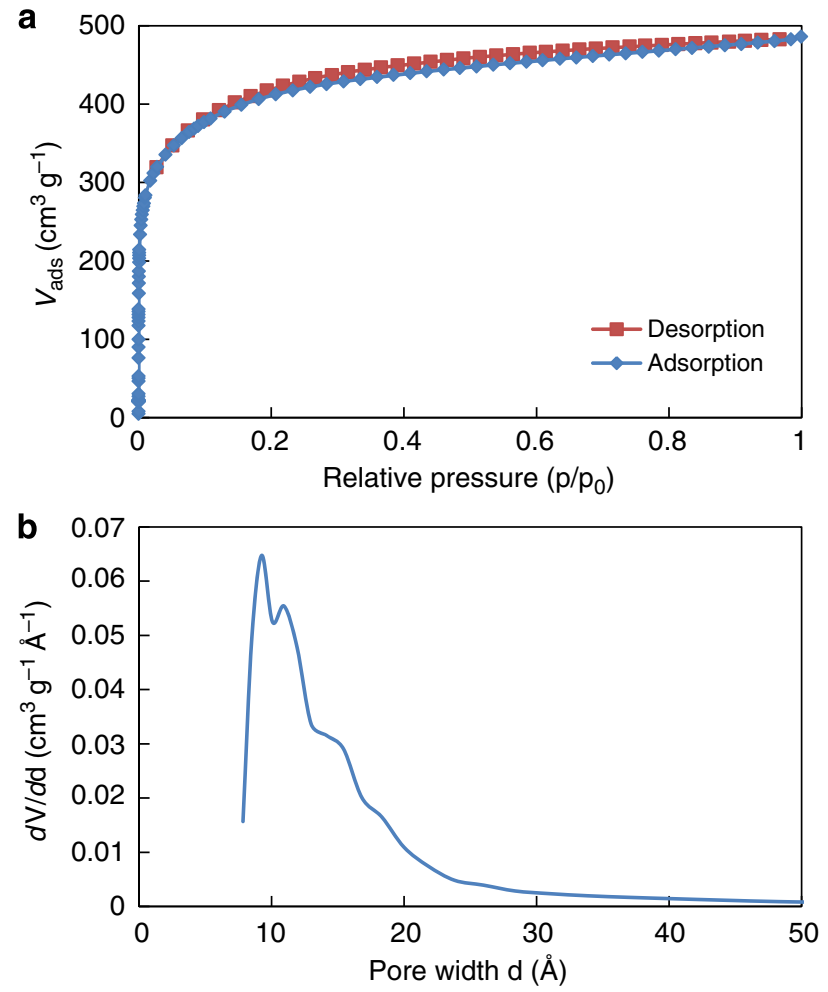

Figure 2 | Pore structure of the BPOE. (a) Results of nitrogen physisorption experiments for the BPOE. (b) Pore-size distribution of the BPOE.

ments, the doped $\mathrm{ClO}_{4}^{-}$state in the BPOE was observed. Thus, the results of the FT-IR and RSMs clearly reveal the successful $p$-doping of $\mathrm{ClO}_{4}^{-}$in the BPOE. Based on this bipolar feature of the BPOE, we can achieve a large working potential window
(4.1-1.3 $\mathrm{V}$ versus $\mathrm{Na} / \mathrm{Na}^{+}$), which can increase the energy density by giving a high-specific capacity. Moreover, its porous morphology results in a high rate capability due to fast ion-transport by the electrolyte filled porous framework (Fig. 2a,b).

In Fig. 4a, we show the charge-discharge curves for the BPOE in a rechargeable sodium battery system at various current densities ranging from $0.01 \mathrm{Ag}^{-1}$ to $5.0 \mathrm{Ag}^{-1}$ in a working potential of 1.3-4.1 V versus $\mathrm{Na} / \mathrm{Na}^{+}$. These curves were then compared with open-circuit voltage $(\mathrm{OCV})$ curves obtained by using the galvanostatic intermittent titration technique (Supplementary Fig. S3). This sloping nature of the charge-discharge curves could be related to the $2 \mathrm{D}$ structure and defects due to the short-rangeordered structure of the BPOE, which results in a different electronic structure compared with the bulk material and affects the electrochemical properties ${ }^{52-54}$. The initial OCV is $\sim 2.8 \mathrm{~V}$ versus $\mathrm{Na} / \mathrm{Na}^{+}$, and therefore, the $p$-dopable and $n$-dopable regions are above and below $2.8 \mathrm{~V}$ versus $\mathrm{Na} / \mathrm{Na}^{+}$, respectively. We used $1 \mathrm{M}$ $\mathrm{NaClO}_{4}$ in PC as an electrolyte due to its high stability in the Na-ion battery system ${ }^{16}$. For a high current density of $5 \mathrm{Ag}^{-1}$, the BPOE can provide a specific capacity of $\sim 50 \mathrm{mAh} \mathrm{g}^{-1}$. To calculate the approximate values for the doping of $\mathrm{Na}^{+}$and $\mathrm{ClO}_{4}^{-}$, we refer to a trimerized $p$-dicyanobenzene (molecular weight of $384.09 \mathrm{~g} \mathrm{~mol}^{-1}$, here referred to as $\mathrm{C}_{3} \mathrm{~N}_{3}$ ) as the unit cell of the BPOE. The two redox reactions can then be defined as

$$
\begin{aligned}
& {\left[\mathrm{C}_{3} \mathrm{~N}_{3}^{+x}\left(\mathrm{ClO}_{4}^{-}\right)_{x}\right]+x \mathrm{Na}^{+}+x \mathrm{e}^{-}} \\
& \rightarrow\left(\mathrm{C}_{3} \mathrm{~N}_{3}\right)+x \mathrm{Na}^{+}\left(\mathrm{ClO}_{4}^{-}\right)
\end{aligned}
$$

for a potential range of $4.1-2.8 \mathrm{~V}$ versus $\mathrm{Na} / \mathrm{Na}^{+}$: that is, the $p$-dopable region, and

$$
\left(\mathrm{C}_{3} \mathrm{~N}_{3}\right)+y \mathrm{Na}^{+}+y \mathrm{e}^{-} \rightarrow\left[\mathrm{C}_{3} \mathrm{~N}_{3}^{-y}\left(\mathrm{Na}^{+}\right)_{y}\right]
$$

for the potential range of $2.8-1.3 \mathrm{~V}$ versus $\mathrm{Na} / \mathrm{Na}^{+}$: that is, $n$-dopable region. 

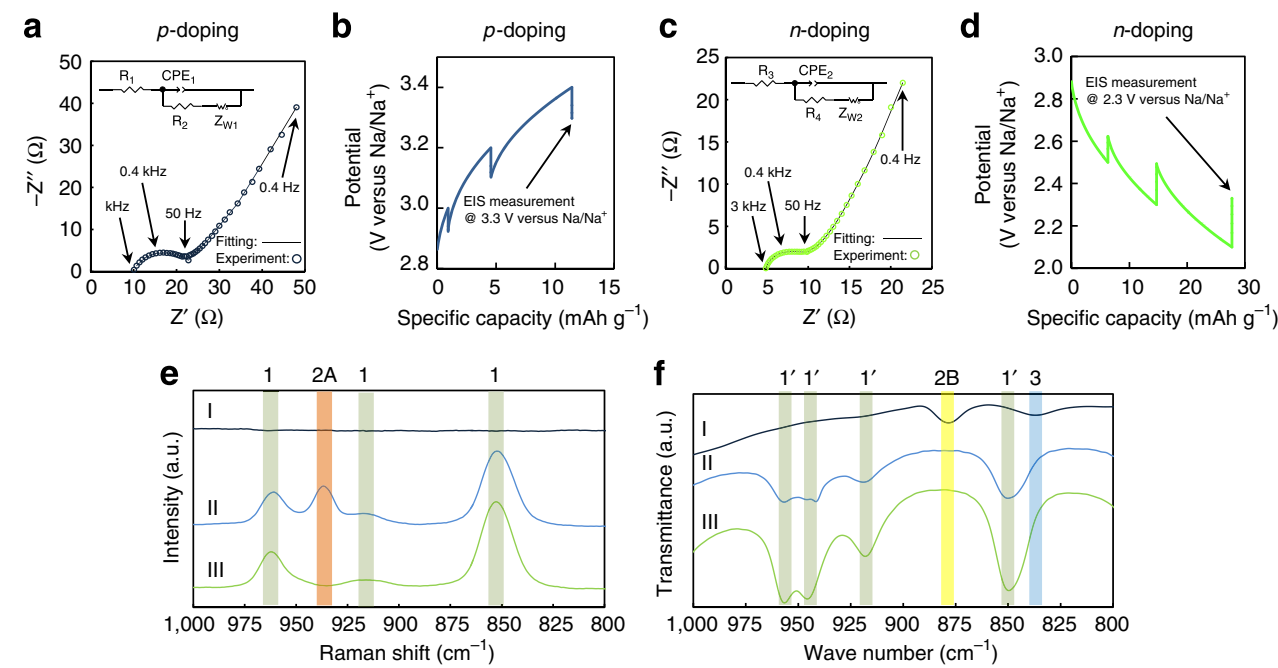

Figure 3 | Electrochemical characteristics of the BPOE. (a) Typical Nyquist plot in the $p$-dopable region and its equivalent circuit. $R_{1}=10.53 \Omega, R_{2}=8.51 \Omega$, $T_{\mathrm{CPE} 1}=437.16 \mu \mathrm{F}$, and $\alpha=0.91$. (b) Potential value at the quasi-equilibrium state for the EIS measurement in the $p$-dopable region. (c) Typical Nyquist plot in the $n$-dopable region and its equivalent circuit. $R_{3}=4.82 \Omega, R_{4}=3.15 \Omega, T_{\text {CPE2 }}=154.13 \mu \mathrm{F}$, and $\alpha=0.92$. (d) Potential value at the quasi-equilibrium state for the EIS measurement in the $n$-dopable region. (e) RSMs for the $\mathrm{ClO}_{4}^{-}$doped $\mathrm{BPOE}$ (indicated as I), $1 \mathrm{M} \mathrm{NaClO}$ in $\mathrm{PC}$ (indicated as II), and PC (indicated as III). (f) FT-IR measurements for I, II and III. (a.u. refers to arbitrary unit).
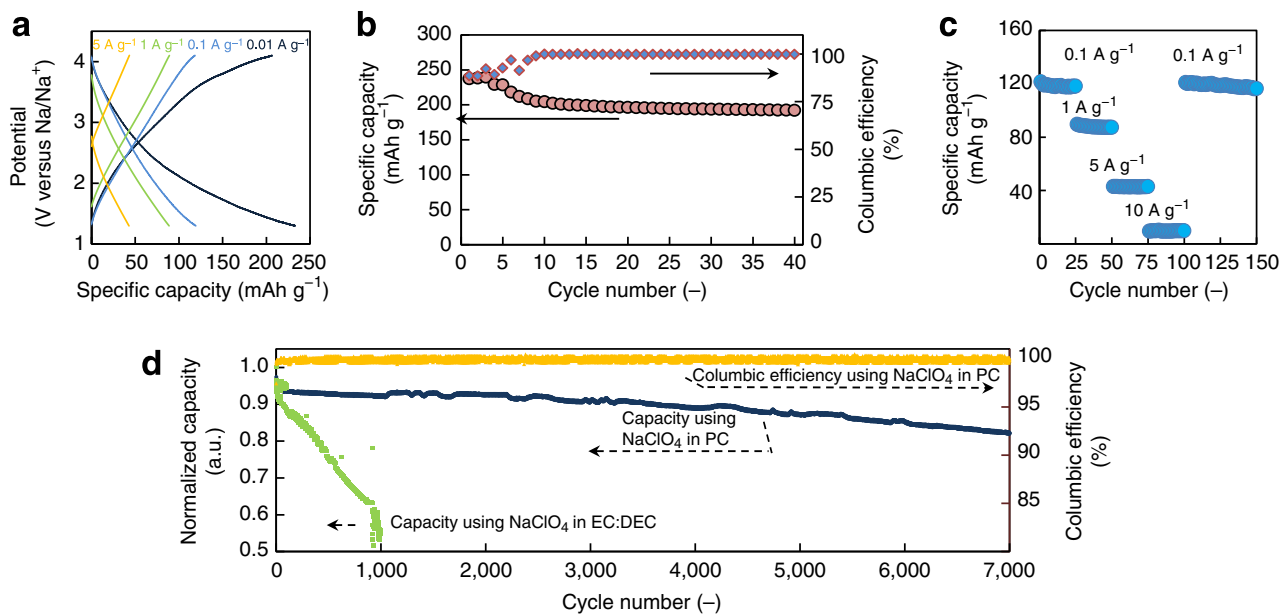

Figure 4 | Cycle performance and rate capability of the BPOE. (a) Charge-discharge curves of a sodium-organic energy storage device at various current densities. (b) Cycle performance of a sodium-organic energy storage device at a current density of $0.01 \mathrm{Ag}^{-1}$. (c) Cycle performance of a sodium-organic energy storage device under harsh conditions. (d) Cycle performance of a sodium-organic energy storage device up to 7,000 cycles with comparing the effect of electrolytes.

A discharge capacity of $55 \mathrm{mAh} \mathrm{g}^{-1}$ ( $p$-undoping) was obtained at a very-low current density of $0.01 \mathrm{Ag}^{-1}$ (Fig. 4a) for equation (1) in the $p$-dopable region $\left(>2.8 \mathrm{~V}\right.$ versus $\left.\mathrm{Na} / \mathrm{Na}^{+}\right)$, resulting in $x=0.79$ from equation (1) and a specific discharge capacity of $185 \mathrm{mAh} \mathrm{g}^{-1}$ (n-doping) was obtained (Fig. 4a) for equation (2) in $n$-dopable region $\left(<2.8 \mathrm{~V}\right.$ versus $\left.\mathrm{Na} / \mathrm{Na}^{+}\right)$, yielding $y=2.65$ from equation (2). The big difference of the discharge capacity for the $p$-undoping and the $n$-doping process could come from the different energy storage mechanism: if we compare the rate capability of the $p$-undoping and $n$-doping processes (Supplementary Table S1), the $p$-undoping process shows a better rate performance compared with the $n$-doping process. This result indicates that the storage mechanism for the $p$-doping/-undoping process (the storage reaction related to $\mathrm{ClO}_{4}^{-}$) could occur at the surface of the BPOE, which is like a pseudo-Faradaic reaction showing a capacitive behaviour. And the $n$-doping/-undoping process is suggested that it could be an insertion/de-insertion of $\mathrm{Na}^{+}$into the BPOE, which is a Faradaic reaction.

Cycle performance and rate capability of the BPOE. The cycle performance of the BPOE was checked at a range current densities, from a very-low current density of $0.01 \mathrm{Ag}^{-1}$ up to a high current density of $5.0 \mathrm{~A} \mathrm{~g}^{-1}$ revealing quite good cycle stability (Fig. $4 \mathrm{a}-\mathrm{c}$ ): At a current density of $0.01 \mathrm{~A} \mathrm{~g}^{-1}$, the BPOE shows a specific capacity of $\sim 200 \mathrm{mAhg}^{-1}$ based on the mass of the BPOE and a stable cycle performance (Fig. 4b). Even under harsh conditions ( 25 cycles at different current densities from $0.1 \mathrm{~A} \mathrm{~g}^{-1}$ to $5.0 \mathrm{Ag}^{-1}$ without relaxation between the cycles), the BPOE reproduces a stable-specific capacity of $\sim 120 \mathrm{mAh} \mathrm{g}^{-1}$ at $0.1 \mathrm{~A} \mathrm{~g}^{-1}$, retaining the same specific capacity as in the first 25 cycles at $0.1 \mathrm{~A} \mathrm{~g}^{-1}$ (Fig. 4c). Moreover, BPOE has been tested over 


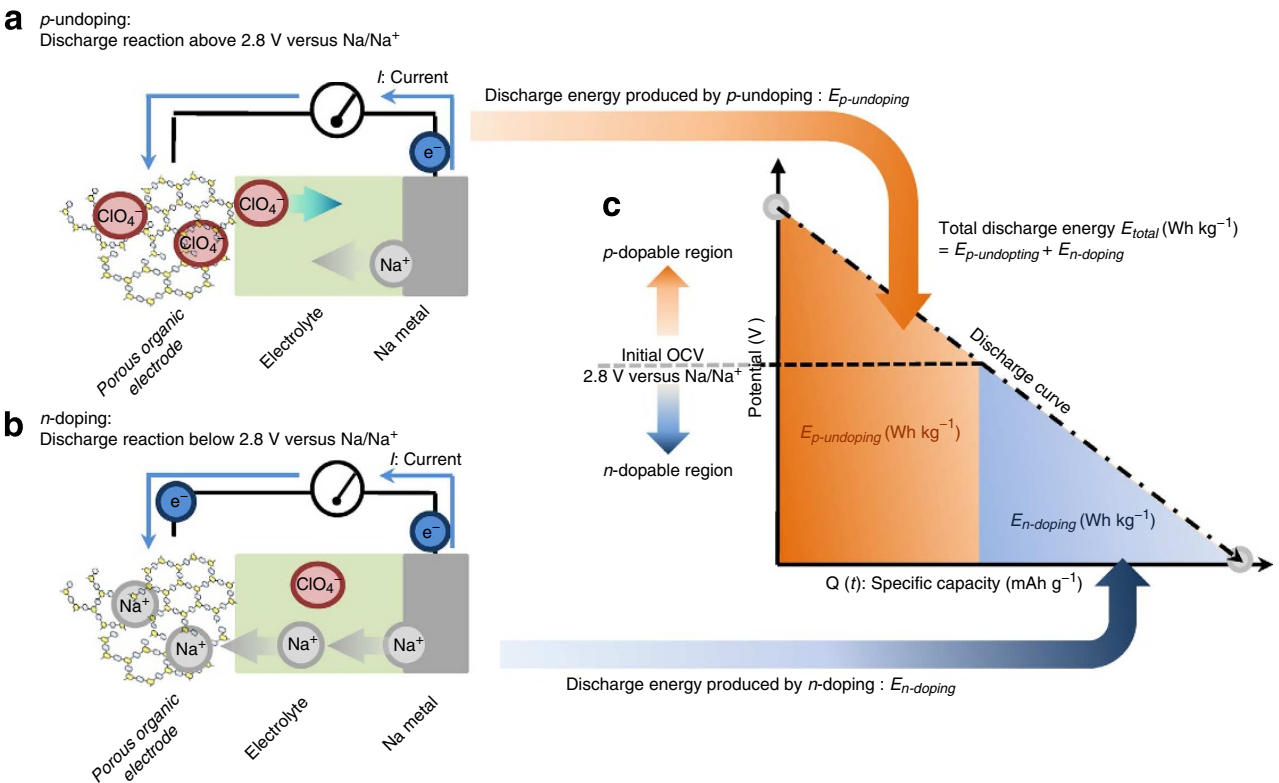

Figure 5 | Energy storage mechanism of the BPOE at discharge process. (a) p-undoping for the discharge process (at the potential above the initial $\mathrm{OCV}$ ) of the BPOE. Electrons are extracted from the anode and are injected into the BPOE. Both anion $\left(\mathrm{ClO}_{4}^{-}\right)$and cation $\left(\mathrm{Na}^{+}\right)$will travel back to the electrolyte during the $p$-undoping discharge process to maintain electrical neutrality. (b) $n$-doping for the discharge process (at the potential below the initial OCV) of the BPOE. Electrons are extracted from the anode and are injected into the BPOE. $\mathrm{Na}^{+}$will be doped into the BPOE during the $n$-doping discharge process to maintain electrical neutrality. (c) Summary of the discharge process of energy storage device using a BPOE, which is linearly, continuously connected $p$-dopable and $n$-dopable region. The total specific energy $E_{\text {total }}\left(\mathrm{Wh} \mathrm{kg}^{-1}\right)$ can be calculated by summing the specific energy obtained during $p$-undoping $E_{\mathrm{p} \text {-undoping }}\left(\mathrm{Wh} \mathrm{kg}^{-1}\right)$, indicated by the red area, and the specific energy obtained during $\mathrm{n}$-doping $E_{\mathrm{n} \text {-doping }}\left(\mathrm{Wh} \mathrm{kg}^{-1}\right)$, indicated by the blue area. $E_{\text {total }}=E_{\mathrm{p} \text {-undoping }+} E_{\mathrm{n} \text {-doping }}$ can be calculated by: $E_{\text {total }}=\int Q(t) V(t) d t$ where $Q(t)\left(\mathrm{mAh} \mathrm{g}^{-1}\right)=$ constant current density $I_{0}\left(\mathrm{mAg}^{-1}\right) \times t(h)$, is the specific capacity, $t(h)$ is the discharge time and $V(t)$ is the potential.

7,000 cycles with $80 \%$ capacity retention at a high current density of $1.0 \mathrm{Ag}^{-1}$ (Fig. 4d). Raman spectra of the electrode after 7,400 charge-discharge cycles provide further evidence of the stability of the 2D framework by showing the $G$ peak (Supplementary Fig. S4). The importance of the selection of the electrolyte is evident by comparing two different electrolytes for the cycle stability test. Both $1 \mathrm{M} \mathrm{NaClO}_{4}$ in ethylene carbonate (EC): diethyl carbonate (DEC) (1:1) and $1 \mathrm{M} \mathrm{NaClO}_{4}$ in PC were reported as stable electrolytes for the $\mathrm{Na}$-ion battery system up to 100 cycles $^{16}$. In contrast to $1 \mathrm{M} \mathrm{NaClO}_{4}$ in PC, the cell with $1 \mathrm{M}$ $\mathrm{NaClO}_{4}$ in EC:DEC begins to show a degradation from about 200 cycles. The reason for the performance degradation may be due to a reaction of the BPOE with the organic solvents and $\mathrm{Na}^{+}$; solid products that were observed to form on the counter electrode ( $\mathrm{Na}$ metal) for the cells, which used $1 \mathrm{M} \mathrm{NaClO}_{4}$ in EC:DEC as electrolyte (Supplementary Fig. S5). This dramatic difference in cycling stability suggests that PC is one of the most stable organic solvents for Na-ion battery systems of this configuration.

Energy storage principle of the BPOE. In Fig. 5a-c, we show the discharge process based on the energy storage principle of a BPOE. The unique points of the BPOE are: (1) this material can be used as a cathode, (2) BPOE is a bipolar material, which has a $p$-dopable region above the initial OCV and a $n$-dopable region below the initial OCV and (3) its $p$-undoping process (Fig. 5a) and $n$-doping process (Fig. $5 \mathrm{~b}$ ) can be continuously and linearly connected $^{29}$ (Fig. 5c). Therefore, we can expect a higher energy density from the BPOE due to a wide working potential compared with a material having only the $p$ - or $n$-dopable property.

\section{Discussion}

The electrochemical property of the porous organic electrode in half-cells is compared with other proposed electrode materials in a Ragone plot (Fig. 6a and Supplementary Fig. S6) and the round-trip energy efficiency (Fig. 6b, Supplementary Figs S6 and S7). Our porous organic electrode exhibits a specific energy of $\sim 500 \mathrm{Wh} \mathrm{kg}^{-1}$ and a specific power of $10 \mathrm{~kW} \mathrm{~kg}^{-1}$ (Fig. 6a); where the weight is based on the mass of BPOE. Promisingly, the volumetric energy is $\sim 250 \mathrm{Wh} \mathrm{L}^{-1}$ (the density of the BPOE is $0.5108 \mathrm{~g} \mathrm{~cm}^{-3}$ ), which may compare favourably to lead-acid or $\mathrm{Ni}-\mathrm{Cd}$ batteries with a specific volumetric energy of $\sim 100 \mathrm{Wh} \mathrm{L}_{\text {cell }}^{-1}$ in full cells. The volumetric energy $\left(\mathrm{Wh} \mathrm{L}^{-1}\right)$ of lead-acid and $\mathrm{Ni}-\mathrm{Cd}$ in full cells is distributed around $100 \mathrm{Wh} \mathrm{L}_{\text {cell }}^{-1}$. Here the volumetric energy of the BPOE is $\sim 250 \mathrm{Wh} \mathrm{L}^{-1}$ considering only the mass of the BPOE. If we assume that the volume of BPOE constitutes $40 \%$ of total volume of a sodium - organic energy storage device, this full cell will provide $\sim 100 \mathrm{Wh} \mathrm{L}_{\text {cell }}^{-1}$, which is as good as for other rechargeable batteries, such as lead - acid and $\mathrm{Ni}-\mathrm{Cd}$ batteries. This result is highly promising. For example, sodium-sulphur (NAS) batteries (indicated as a yellow region in Fig. 4a) are a promising energy storage device for stationary electricity storage uses ${ }^{4,8}$. NAS batteries have a theoretical specific energy of $975 \mathrm{Wh} \mathrm{kg}^{-1}$ for the following reactions (equation (3), a theoretical specific capacity of $487 \mathrm{mAh} \mathrm{g}^{-1}$ with an average cell voltage of $\sim 2 \mathrm{~V}$ ):

$$
2 \mathrm{Na}+2 \mathrm{~S} \rightleftarrows \mathrm{Na}_{2} \mathrm{~S}_{2}
$$

However, this system has safety problems due to its high operation temperature of $300-350^{\circ} \mathrm{C}$ (ref. 8). Indeed, full cells can provide much less specific energy due to limited practical cell configurations related to this safety problem. In contrast, we can 

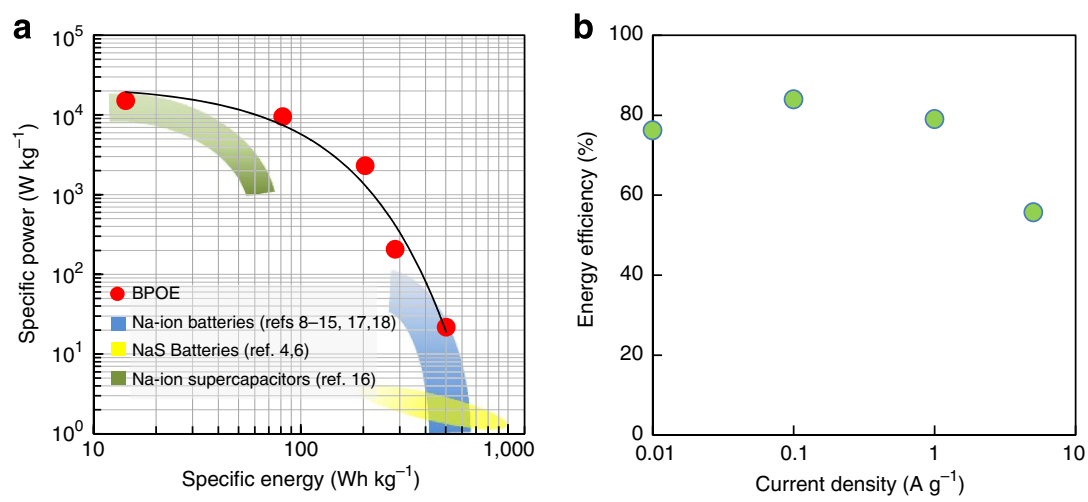

Figure 6 | Ragone plots and round-trip energy efficiency of sodium-organic energy storage device. (a) Ragone plots for a sodium-organic energy storage device using a BPOE and various sodium-based energy storage devices in half-cells. The specific energy was calculated on the basis of the half-cells using sodium metal as an anode. (b) Round-trip energy efficiency of the sodium-organic energy storage device.

operate the porous organic electrode at room-temperature with a specific energy comparable to NAS batteries. Also, this system shows a longer cycle life of 7,000 cycles compared with 4,500 cycles for NAS batteries and the energy efficiency of the BPOE is $\sim 80 \%$ (Fig. 6b), which is comparable to $85 \%$ of NAS batteries ${ }^{8}$, and higher than $\sim 70 \%$ of redox-flow batteries ${ }^{55}$, but the self-discharge characteristic of the NAS and sodium-ion batteries based on the intercalation mechanism are better than for the BPOE electrodes (Supplementary Fig. S8). These issues could be improved by optimization of electrode assembly processes and further fundamental investigations of the BPOE, especially on the energy storage mechanism. The key point is that the porous organic electrode has a remarkably high-specific power of $10 \mathrm{~kW} \mathrm{~kg}^{-1}$; a performance not yet reached in Na-ion batteries. These properties of the BPOE are comparable to O3-type $\mathrm{NaNi}_{0.5} \mathrm{Mn}_{0.5} \mathrm{O}_{2}$ (ref. 16) and P2-type $\mathrm{Na}_{\mathrm{x}}\left[\mathrm{Fe}_{1 / 2} \mathrm{Mn}_{1 / 2}\right] \mathrm{O}_{2}$ (ref. 6), which are performed as state-ofthe-art high-performance cathodes for $\mathrm{Na}$-ion batteries, and are much higher than for other intercalation compounds such as fluorophosphates $^{12,13}$, NASICONs ${ }^{14}$ and olivines ${ }^{15}$. By combing state-of-the-arts anodes $27,56,57$, and electrolytes, such as ionic liquids ${ }^{58}$ or $\mathrm{NaPF}_{6}$ in EC:PC (ref. 59), the safety problem, which is one of the most important points for any practical technology, of a sodium-organic energy storage device could be improved.

In summary, we have demonstrated the excellent electrochemical performance of a porous organic electrode for sodiumbased energy storage devices with even compared with other sodium battery systems, and it is, therefore, a promising material for next-generation energy storage devices. This is, to the best our knowledge, the first report of a high-performance sodium-based energy storage device using an organic cathode. BPOEs are a new material platform to develop alternative, high-performance rechargeable energy storage devices by using cost-effective and abundant organic materials.

\section{Methods}

Synthesis of the porous organic electrode. The BPOE was synthesized by ionothermal synthesis ${ }^{30}$; heating a mixture of $p$-dicyanobenzene and $\mathrm{ZnCl}_{2}$ in quartz ampules at $400^{\circ} \mathrm{C}$ for $40 \mathrm{~h}$. The obtained samples were washed with $1 \mathrm{M}$ $\mathrm{HCl}$ and distilled water for several times. After drying, we used this material as the BPOE without further treatments. The conductivity of the as-prepared BPOE was $4.09 \times 10^{-6} \mathrm{~S} \mathrm{~cm}^{-1}$ at $25^{\circ} \mathrm{C}$, which agrees well with the values for non-doped conjugated polymers ${ }^{60}$. The conductivity was measured by the impedance spectroscopy technique (see Supplementary Discussion). We used steel electrodes and held a pellet of the as-prepared BPOE by using them to measure the impedance spectroscopy response. A frequency range from $10 \mathrm{mHz}$ to $10 \mathrm{kHz}$ with an amplitude of $500 \mathrm{mV}$ was applied.

Physical characterizations. The electron energy-loss spectroscopy measurements were carried out using a Tecnai F30 (FEI company, equipped with a Gatan GIF 200 imaging energy filter) operated at an acceleration voltage of $300 \mathrm{kV}$ by using a special sample holder, which can keep the organic specimen cool. The FT-IR measurement was carried out by using a FT-IR-6200 (JASCO) with KBr-IR measurements. The RSMs were carried out by using a Ventuno (NSR-1000DT, JASCO) with a laser excitation of $632.8 \mathrm{~nm}$ from a He-Ne laser. We have prepared samples for the spectroscopic measurements by the following method: the electrochemical doping of $\mathrm{ClO}_{4}^{-}$in the BPOE was carried out by using galvanostatic intermittent titration technique. After the electrochemically doping, the doped BPOE was washed by PC and measured the Raman spectra. The powder X-ray diffraction measurement was carried out on a Stadi P (STOE) diffractometer using $\mathrm{Cu} \mathrm{K \alpha}{ }_{1}$ radiation. The nitrogen physisorption measurements were carried out at $77 \mathrm{~K}$ up to 1 bar using a Quantachrome Autosorb 1C apparatus. Pore size distribution was obtained by applying the QS-DFT equilibrium model for nitrogen on carbon with slit pores at $77 \mathrm{~K}$.

Electrochemical characterization. Electrodes were made by mixing active material (70 wt.\%), carbon (carbon black; 20 wt.\%), and binder (carboxyl methyl cellulose; 10 wt.\%). We used Al current collectors. The loading mass was $\sim 1.5 \mathrm{mg}$ $\mathrm{cm}^{-2}$ and the electrode thickness was $\sim 100 \mu \mathrm{m}$. We assembled the cells in a purge-type dry glove box (MIWA MFG) filled with high purity Ar gas

$(\mathrm{N} 50=99.999 \%)$ and tested them on a multichannel potentiostatic-galvanostatic system (SD-8, Hokuto-denko) and a frequency response analyser (SI 1250, Solatron). We used sodium metal as an anode and a reference electrode. We used $1 \mathrm{M}$ $\mathrm{NaClO}_{4}$ in propylene carbonate (Kishida Chemicals) as an electrolyte and in a three-electrode beaker cell as the test cell. The charge-discharge properties were recorded in a potential range from 4.1 to $1.3 \mathrm{~V}$ versus $\mathrm{Na} / \mathrm{Na}^{+}$. EIS measurements were carried out at $3.3 \mathrm{~V}$ versus $\mathrm{Na} / \mathrm{Na}^{+}$( $p$-dopable region) and $2.3 \mathrm{~V}$ versus $\mathrm{Na} /$ $\mathrm{Na}^{+}(n$-dopable region) after achieving each quasi-equilibrium state by taking a rest of $1 \mathrm{~h}$ after the doping. A frequency range from $10 \mathrm{mHz}$ to $10 \mathrm{kHz}$ with an amplitude of $10 \mathrm{mV}$ was applied for the EIS measurements. The fitting was carried out by using Z-View (Scribner Associates). We have measured all charge-discharge properties after charging till $4.1 \mathrm{~V}$ versus $\mathrm{Na} / \mathrm{Na}^{+}$( $p$-doped state of the BPOE).

Calculation of specific power $(\boldsymbol{P})$ and specific energy $(\boldsymbol{E})$. Specific energy $E$ (Wh kg ${ }^{-1}$ ) can be calculated by $E=\int_{0}^{t_{\text {cut }}} \frac{P_{0}}{m} V(t) d t$ where $t_{\text {cut }}$ (hour) is a discharge time, $I_{0}(\mathrm{~A})$ is a constant current, $m(\mathrm{~kg})$ is a mass of the active material, and $V(t)$ is a time-dependent voltage in the dimension of V. Specific power $P\left(\mathrm{~W} \mathrm{~kg}^{-1}\right)$ can be calculated by $P=E / t_{\text {cut }}$. Also see Supplementary Figs S6, S7.

\section{References}

1. Tarascon, J.-M. Key challenges in future Li-battery research. Phil. Trans. R. Soc. A 368, 3227-3341 (2010).

2. Tarascon, J.-M. Is lithium new gold? Nat. Chem. 2, 510 (2010).

3. Kim, S. W., Seo, D. H., Ma, X., Ceder, G. \& Kang, K. Electrode materials for rechargeable sodium-ion batteries: potential alternatives to current lithium-ion batteries. Adv. Energy. Mater. 2, 710-721 (2012).

4. Ellis, B. L. \& Nazar, L. F. Sodium and sodium-ion energy storage batteries. Curr. Opin. Solid State Mater. Sci. 16, 168-177 (2012).

5. Slater, M. D., Kim, D., Lee, E. \& Johnson, C. S. Sodium-ion batteries. Adv. Funct. Mater. doi:10.1002/adfm.201200691 (in press).

6. Yabuuchi, N. et al. P2-type $\mathrm{Na}_{\mathrm{x}}\left[\mathrm{Fe}_{1 / 2} \mathrm{Mn}_{1 / 2}\right] \mathrm{O}_{2}$ made from earth-abundant elements for rechargeable Na batteries. Nat. Mater. 11, 512-517 (2012)

7. Whittingham, M. S. Chemistry of intercalation compounds-metal guests in chalcogenide hosts. Prog. Solid State Chem. 12, 41-99 (1978).

8. Oshima, T., Kajita, M. \& Okuno, A. Development of Sodium-Sulfur Batteries. Int. J. Appl. Ceram. Technol. 1, 269-276 (2004).

9. Newman, G. H. \& Klemann, L. P. Ambient-temperature cycling of a Na-TiS 2 cell. J. Electrochem. Soc. 127, 2097-2099 (1980). 
10. Delmas, C., Braconnier, J.-J., Fouassier, C. \& Hagenmuller, P. Electrochemical intercalation of sodium in $\mathrm{Na}_{\mathrm{x}} \mathrm{CoO}_{2}$ bronzes. Solid State Ion. 3-4, 165-169 (1981).

11. Lu, Z. \& Dahn, J. R. In-situ X-ray diffraction study of $\mathrm{P} 2-\mathrm{Na}_{2 / 3}\left[\mathrm{Ni}_{1 / 3} \mathrm{Mn}_{2 / 3}\right] \mathrm{O}_{2}$. J. Electrochem. Soc. 148, A1225-A1229 (2001).

12. Ellis, B. L., Makahnouk, W. R. M., Makimura, Y., Toghill, K. \& Nazar, L. F. A multifunctional $3.5 \mathrm{~V}$ iron-based phosphate cathode for rechargeable batteries. Nat. Mater. 6, 749-753 (2007).

13. Recham, N. et al. Ionothermal synthesis of sodium-based fluorophosphate cathode materials. J. Electrochem. Soc. 156, A993-A999 (2009).

14. Plashnista, L. S., Kobayashi, E., Noguchi, Y., Okada, S. \& Yamaki, J. Performance of NASICON symmetric cell with ionic liquid electrolyte. J. Electrochem. Soc. 157, A536-A534 (2010).

15. Lee, K. T., Ramesh, T. N., Nan, F., Botton, G. \& Nazar, L. F. Topochemical synthesis of sodium metal phosphate olivines for sodium-ion batteries. Chem. Mater. 23, 3593 (2011).

16. Komaba, S. et al. Electrochemical $\mathrm{Na}$ insertion and solid electrolyte interphase for hard-carbon electrodes and application to Na-Ion batteries. Adv. Funct. Mater. 21, 3859-3867 (2011).

17. Chen, Z. et al. High-performance sodium-ion pseudocapacitors based on hierarchically porous nanowire composites. ACS Nano. 6, 4319-4327 (2012).

18. Hosono, E. et al. High power Na-ion rechargeable battery with singlecrystalline $\mathrm{Na}_{0.44} \mathrm{MnO}_{2}$ nanowire electrode. J. Power Sources 217, 43-46 (2012).

19. Novák, P., Müller, K., Santhanam, S. V. \& Hass, O. Electrochemically active polymers for rechargeable batteries. Chem. Rev. 97, 207-281 (1997).

20. Liang, Y., Tao, Z. \& Chen, J. Organic electrode materials for rechargeable lithium batteries. Adv. Energy Mater. 2, 742-769 (2012).

21. Nishide, H. \& Oyaizu, K. Toward flexible batteries. Science 319, 737-738 (2008).

22. MacInnes, D., Druy, M. A., Nigery, P. J., Nairns, D. P., MacDiramid, A. G. \& Heeger, A. J. Organic batteries: reversible $n$ - and $p$-Type electrochemical Doping of polyacetylene, $(\mathrm{CH})_{\mathrm{x}}$. J. Chem. Soc., Chem. Commun. 7, 317-319 (1981).

23. Schacklette, L. W., Toth, J. E., Murthy, N. S. \& Baugham, R. H. Polyacetylene and polyphenylene as anode materials for nonaqueous secondary batteries. J. Electrochem. Soc. 132, 1529-1535 (1985).

24. Hérold, C., Billaud, D. \& Yazami, R. Electrochemical doping of polyparaphenylene with alkali metals in solid state cells. Solid State Ion. 40-41, 985-987 (1990)

25. Chen, $\mathrm{H}$. et al. From biomass to a renewable $\mathrm{Li}_{\mathrm{x}} \mathrm{C}_{6} \mathrm{O}_{6}$ organic electrode for sustainable Li-ion batteries. ChemSusChem. 1, 348-355 (2008).

26. Suga, T., Sugita, S., Ohshiro, H., Oyaizu, K. \& Nishide, H. $p$ - and $n$-type bipolar redox-active radical polymer: toward totally organic polymer-based rechargeable devices with variable configuration. Adv. Mater. 23, 751-754 (2011).

27. Zhao, L. et al. Disodium terephthalate $\left(\mathrm{Na}_{2} \mathrm{C}_{8} \mathrm{H}_{4} \mathrm{O}_{4}\right)$ as high performance anode material for low-cost room-temperature sodium-ion battery. Adv. Energy Mater. 2, 962-965 (2012).

28. Shirakawa, H., Louis, E. J., MacDiarmid, A. G., Chiang, C. K. \& Heeger, A. J. Synthesis of electrically conducting organic polymers: halogen derivatives of polyacetylene, $(\mathrm{CH})_{x}$. J. Chem. Soc., Chem. Commun. 16, 578-580 (1977).

29. Sakaushi, K. et al. An energy storage principle using bipolar porous polymeric frameworks. Angew. Chem. Int. Ed. 51, 7850-7854 (2012).

30. Kuhn, P., Antonietti, M. \& Thomas, A. Porous, covalent triazine-based frameworks prepared by ionothermal synthesis. Angew. Chem. Int. Ed. 47, 3450-3453 (2008).

31. Kuhn, P., Antonietti, M. \& Thomas, A. Toward tailorable porous organic polymer networks: a high-temperature dynamic polymerization scheme based on aromatic nitriles. Macromolecules 42, 319-326 (2009).

32. Tuinstra, F. \& Koenig, J. L. Raman spectrum of graphite. J. Chem. Phys. 53, 1126-1130 (1970).

33. Lespade, P., Al-Jishi, R. \& Dresselhaus, M. S. Model for Raman scattering from incompletely graphitized carbons. Carbon 20, 427-431 (1982).

34. Ferrari, A. C. et al. Raman spectrum of graphene and graphene layers. Phys. Rev. Lett. 97, 187401 (2006).

35. Hellgren, N., Johansson, M. P., Broitman, E., Hultman, L. \& Sundgren, J.-E. Role of nitrogen in the formation of hard and elastic $\mathrm{CN}_{x}$ thin films by reactive magnetron sputtering. Phys. Rev. B 59, 5162-5169 (1999).

36. Ferrari, A. C. \& Robertson, J. Raman spectroscopy of amorphous, nanostructured, diamond-like carbon, and nanodiamond. Phil. Trans. R. Soc. Lond. A 362, 2477-2512 (2004).

37. Zheng, T., Xing, W. \& Dahn, J. R. Carbons prepared from coals for anode of lithium-ion cells. Carbon 34, 1501-1507 (1996).

38. Thomas, A. et al. Graphitic carbon nitride materials: variation of structure and morphology and their use as metal-free catalysts. J. Mater. Chem. 18, 4893-4908 (2008).

39. Novoselov, K. S. et al. Two-dimensional atomic crystals. Proc. Natl Acad. Sci. USA 102, 10451-10453 (2005)

40. Geim, A. K. \& Novoselov, K. S. The rise of graphene. Nat. Mater. 6, 183-191 (2007).

41. Goettmann, F., Fischer, A., Antonietti, M. \& Thomas, A. Chemical synthesis of mesoporous carbon nitrides using hard templates and their use as a metal-free catalyst for Friedel-Crafts reaction of benzene. Angew. Chem. Int. Ed 45, 4467-4471 (2006).

42. Cooper, A. I. Conjugated Microporous Polymers. Adv. Mater. 21, 1291-1295 (2009).

43. Bieri, M. et al. Porous graphenes: two-dimensional polymer synthesis with atomic precision. Chem. Commun. 45, 6919-6921 (2009).

44. Weber, J., Bojdys, M. J. \& Thomas, A. Polymeric Frameworks: toward porous semiconductors. in Supramolecular Soft Matter: Applications in Materials and Organic Electronics (ed. Nakanishi, T.) (John Wiley \& Sons, Inc., 2011).

45. Wang, Y., Wang, X. C. \& Antonietti, M. Polymeric graphitic carbon nitride as a heterogeneous organocatalyst: from photochemistry to multipurpose catalysis to sustainable chemistry. Angew. Chem. Int. Ed. 51, 68-89 (2012).

46. Okubo, M. et al. Fast Li-Ion Insertion into nanosized $\mathrm{LiMn}_{2} \mathrm{O}_{4}$ without domain boundaries. ACS Nano. 4, 741-752 (2010).

47. Ho, C., Raistrick, I. D. \& Huggins, R. A. Application of A-C techniques to the study of lithium diffusion in tungsten trioxide thin films. J. Electrochem. Soc. 127, 343-350 (1980).

48. Miller, A. G. \& Macklin, J. W. Vibrational spectroscopic studies of sodium perchlorate contact ion pair formation in aqueous solution. J. Phys. Chem. 89, 1193-1201 (1985).

49. Schantz, S., Torell, L. M. \& Stevens, J. R. Raman and Brillouin scattering of $\mathrm{LiClO}_{4}$ complex in poly(propylene-glycol). J. Appl. Phys. 64, 2038-2043 (1988)

50. Nunes, S. C. et al. Spectroscopic and structural studies of di-ureasils doped with lithium perchlorate. Electrochim. Acta. 53, 1466-1475 (2007).

51. Sinha, R. K., Nicol, E., Steinmetz, V. \& Maitre, P. Gas phase structure of micro-hydrated $\left[\mathrm{Mn}\left(\mathrm{ClO}_{4}\right)\right]^{+}$and $\left[\mathrm{Mn}_{2}\left(\mathrm{ClO}_{4}\right)_{3}\right]^{+}$ions probed by infrared spectroscopy. J. Am. Soc. Mass. Spectrom 21, 758-772 (2010).

52. Kudo, T. \& Hibino, M. Consideration on the potential-composition relationships observed with amorphous intercalation systems such as $\mathrm{Li}_{\mathrm{x}} \mathrm{WO}_{3}$. Solid State Ion 84, 65-72 (1996).

53. Okubo, M. et al. Nanosized effect on high-rate li-ion intercalation in $\mathrm{LiCoO}_{2}$ electrode. J. Am. Chem. Soc. 129, 7444-7452 (2007).

54. Okubo, M., Kim, J., Kudo, T., Zhou, H. S. \& Honma, H. Anisotropic surface effect on electronic structures and electrochemical properties of $\mathrm{LiCoO}_{2}$. J. Phys. Chem. C 113, 15337-15342 (2009).

55. Ponce de León, C., Frías-Ferrer, A., González-García, J., Szánto, D. A. \& Walsh F. C. Redox flow cells for energy conversion. J. Power Sources 116, 716-732 (2006).

56. Chevrier, V. L. \& Ceder, G. Challenges for Na-ion negative electrodes. J. Electrochem. Soc. 158, A1011-A1014 (2011).

57. Senguttuvan, P., Rousse, G., Seznec, V., Tarascon, J.-M. \& Palacín, M. R. $\mathrm{Na}_{2} \mathrm{Ti}_{3} \mathrm{O}_{7}$ : lowest voltage ever reported oxide insertion electrode for sodium ion batteries. Chem. Mater. 23, 4109-4111 (2011).

58. Fukunaga, A. et al. Intermediate-temperature ionic liquid NaFSA-KFSA and its application to sodium secondary batteries. J. Power Sources 203, 52-56 (2012)

59. Ponrounch, A., Marchante, E., Coutry, M., Tarascon, J.-M. \& Palacín, M. R In search of an optimized electrolyte for Na-ion batteries. Energy Env. Sci. 5, 8572-8583 (2012).

60. MacDiarmid, A. G. 'Synthetic Metals': A Novel Role for Organic Polymers (Novel Lecture). Angew. Chem. Int. Ed. 40, 2581-2590 (2001).

\section{Acknowledgements}

We thank Dr Peter Dunne (IFW Dresden, ICM) for fruitful discussions and comments. Dr Steven Johnston (The University of British Columbia) and members of the TU Dresden, AIST and IFW Dresden, ICM are acknowledged for supports. K.S. is supported by German Academic Exchange Service, DAAD (Grant number: A/09/74990).

\section{Author contributions}

K.S. conceived, designed, and coordinated the study. E.H. established the sodium battery system at AIST and advised for the experiments. K.S. and G.N. carried out and data collected experiments. T.G. operated the TEM. K.S., E.H. and H.S.Z. analysed the results of electrochemical measurements. K.S. wrote and E.H., G.N., T.G., H.S.Z., S.K. and J.E. edited the manuscript. All authors discussed the results and commented on the manuscript.

\section{Additional information}

Supplementary Information accompanies this paper at http://www.nature.com/ naturecommunications

Competing financial interests: The authors declare no competing financial interests.

Reprints and permission information is available online at http://npg.nature.com/ reprintsandpermissions/

How to cite this article: Sakaushi, K. et al. Aromatic porous-honeycomb electrodes for a sodium-organic energy storage device. Nat. Commun. 4:1485 doi: 10.1038/ncomms2481 (2013). 